http://dx.doi.org/10.5007/1677-2954.2013v12n2p272

\title{
OS MOMENTOS CONSTITUTIVOS DO CUIDADO E O DASEIN COMO SER DE RELAÇÕES.
}

\author{
THE CONSTITUTIVE MOMENTS OF CARE AND DASEIN AS A \\ BEING OF RELATIONS.
}

\author{
EVANDRO BILIBIO \\ (UFFS/Brasil)
}

\begin{abstract}
RESUMO
Este artigo tem por objetivo mostrar que o Dasein é um ser de relações. Para tanto, toma-se a obra Ser e Tempo de Heidegger como horizonte de todas as considerações que aqui forem feitas. Em especial no que diz respeito a ideia de mundo tal qual é expresso na obra de 1927, bem como a noção de cuidado. O intuito é mostrar que, ao final, o Dasein não é um sujeito puramente metafísico fechado e isolado dentro de um mundo. A constatação (convicção talvez seja melhor) de que o mesmo é antes de tudo e qualquer coisa ser-no-mundo feita pelo autor da obra supracitada é imprescindível para que seja compreendido que seus momentos existenciais determinam as relações entre ele e os entes intramundanos. Como consequência emerge a ideia de que há uma responsabilidade implícita na noção de cuidado e que determina todo tipo possível de relação. Levando em consideração que as questões relativas à bioética e a ética ambiental dizem respeito ao modo como o homem se encontra no mundo e estabelece relações, pode-se afirmar que há um modo de estar no mundo mais originário, ou ético, que possibilita uma compreensão diferenciada dele e de seus problemas.
\end{abstract}

Palavras-chave: Mundo; Cuidado, Bioética, Relações.

\begin{abstract}
This article aims to demonstrate that the Dasein is a Being of relationships. Therefore, it takes Being and Time as the horizon of all the considerations that are made in here. In particular the idea of the world as it is expressed in the 1927's work and the notion of care, as well. The intent is inferred that the Dasein is not a purely metaphysical subject closed and isolated within a world. The statement (maybe conviction is a better word for this) it is that the Dasein, first of all, is the notion of being in the world made by the author in the mentioned work it is essential to be understood how their existential moments determine the relation between Dasein and the innerworldly entities. Emerges as a consequence the idea that there is a responsibility implicit in the notion of care that determines every possible kind of relationship. Whereas that the issues of bioethics and environmental ethics relate to how the man is in the world and establish relationships, it can be stated that there is a way of being in the world that is most original, or most ethical, which enables a nuanced understanding about him and his issues.
\end{abstract}

Keywords: World; Care; Bioethics; Relationships 
Muitas vezes pode passar despercebido aos leitores de Ser e Tempo a afirmação de que ser-no-mundo é o fio condutor, bem como está á base, de todas as considerações tecidas sobre o Dasein. No ser desse ente, o cuidado (Sorge) é onde aquela afirmação ganhará formas e desdobramento claros; deixando a mostra o seu caráter relacional. Somando-se a isso as questões e problemas ligados à autenticidade parecem deixar claro que a responsabilidade é um tema que se desdobra naturalmente dessas questões. Assim, a noção de cuidado de Heidegger (Sorge) implica necessariamente em uma ideia de responsabilidade. Uma responsabilidade de caráter ontológica implícita àquela, mas que tem uma implicação direta no comportamento e no modo como o Dasein compartilha o mundo. Mundo, aqui, no sentido de mundo compartilhado com outros entes. Desse modo, se o homem é ser no mundo, se implícita à noção de cuidado há uma ética/moral e mundo é sempre mundo compartilhado, necessariamente é possível desenvolver elementos de uma filosofia moral, como a noção de responsabilidade, das convicções heideggerianas. Se o Dasein é antes de tudo ser no mundo e esse mundo é mundo compartilhado, então, seja lá o que pode ser esse mesmo Dasein ele o é nesse mesmo compartilhar.

A questão temporal é importante na medida em que esse modo de ser no mundo é determinado pelo tempo. O modo como o existente vive e compartilha o mundo, ou seja, tem as suas vivências com outros entes é determinado temporalmente. Assim, à noção de responsabilidade, implícita ao ser do Dasein, também é determinada pelo tempo. Entendase, aqui, o modo como o ente humano projeta-se para aquelas possibilidades que lhe são apresentadas em sua existência. Desse modo, a noção de responsabilidade é em si mesma, temporal, pois, passado, presente e futuro articulam-se de modo a possibilitar a opção do ser humano por esse ou aquele comportamento.

As ideias, entre outras, que o mundo é compartilhado bem como a de que o existente humano é ser no mundo implicam que deve ser afastada a ideia de que o modo autêntico em que o Dasein assume a si mesmo e foge do público, da impessoalidade, não é uma fuga propriamente dita de si mesmo ou do mundo. Colocar-se em um modo autêntico de existir não é fugir do convívio social, fugir de suas obrigações, renegar o outro. Pelo contrário, é colocar-se diante de tudo que se apresenta no cotidiano de um modo diferente. 
A autenticidade, longe de impor que nos fechemos para o mundo partilhado, solicita-nos a habitar este mundo de uma forma autoconsciente e a reconhecer a constituição social do ser humano, ao mesmo tempo que se recusa a perder-se nos modos dominantes de competição que inibem a sua reflexão, ou meditação, ontológica. (THIELE, 1995, p.77)

Esse colocar-se não é ainda uma postura cognitiva. É, antes, uma postura ontológica da qual surgirá a possibilidade de uma postura diferenciada e, como tal, do surgimento de uma filosofia moral. Assim, é necessário ser conservado o horizonte de que o Dasein compartilha mundo e que o modo de ser autêntico não significa em fugir, mas relacionar-se de modo diferenciado com os outros entes.

A questão da autenticidade, por outro lado, relaciona-se com a possibilidade de um poder ser todo, inerente à constituição ontológica de cada Dasein, que diz respeito e implica em uma responsabilidade desse ente para consigo mesmo antes de qualquer responsabilidade para com o outro. Ao final, há dois horizontes de responsabilidade, um com respeito aos entes enquanto compartilham um espaço comum e outro com respeito a si mesmo. Esse último condiciona o outro. Desse modo, o ser aí deve, primeiro, assumir a responsabilidade para consigo mesmo, para com seu ser e, assim, poder colocar-se de modo adequado no mundo. Essa mudança é que pode possibilitar o surgimento de uma ética/moral correspondente por possibilitar uma compreensão mais profunda do Dasein enquanto ser-com (outros entes).

Levando-se em consideração a possibilidade de uma ética originária, tal qual foi sugerida na Carta sobre o Humanismo, de 1934, essa deve ser pensada fora do que tradicionalmente identifica-se como éticas normativas ou uma ética das virtudes. Do mesmo modo, essa ética originária que supõe uma nova noção de responsabilidade possibilita, necessariamente, uma realocação do homem com relação ao que chama-se mundo e natureza. Isso significa repensar aquilo a partir do qual o homem diferencia-se e, em grande medida, delimita a noção de identidade humana. Essa nova noção mais ampliada leva a repensar, igualmente, questões morais ligadas à relação do homem com o meio ambiente, com os animais e com seus semelhantes. Nesse último caso, é possível reconsiderar questões tais como aborto, pena de morte, etc. 
A responsabilidade mostra-se em toda sua extensão como tendo, antes de qualquer coisa, um horizonte originário no sentido heideggeriano do termo. A tarefa que resta é determinar, antes de qualquer coisa, a noção de uma responsabilidade originária com o papel da decisão, diante da qual o ser-aí coloca-se entre o assumir ou não uma existência autêntica e, portanto, saindo da impessoalidade e do público. Essa atitude para consigo determina o modo como se estrutura o espaço de convivência com os outros entes, como dito antes.

Nesse ponto não há mais espaço para a passividade, ou seja, o sair da impessoalidade exige necessariamente uma tomada de posição do Dasein com relação a sua existência e que implicará no modo como se relacionará com o mundo. E Heidegger sustenta em Ser e Tempo que há uma espécie de tendência ontológica ao ser-aí em assumir um tipo de comportamento que o coloca fora da impessoalidade. Contudo e, paradoxalmente, esse comportamento é relegado a um segundo plano. Pois da mesma forma que há a tendência do ser-aí para sair da impessoalidade que é testemunhada pelo chamamento silencioso da consciência, o Dasein permanece decaído naquela impessoalidade ignorando aquela mesma tendência ou chamado. Aquela possibilidade não é desconhecida, ou seja, o chamamento da consciência para que o ser aí coloque-se de modo diferenciado no mundo. ${ }^{2}$

Há uma relação, portanto, entre o ser do Dasein e seus momentos constitutivos com a possibilidade de um assumir-se diferenciados frente às situações concretas. Assim, será feita uma explanação da estrutura do cuidado mostrando o quanto ela é temporal e como a possibilidade de um colocar-se de modo diferenciado junto aos outros entes relaciona-se com os momentos existenciais que constituem essa estrutura. Isso possibilita, também, verificar o quanto esse movimento depende da decisão.

Ao cuidado pertence a possibilidade de um poder-ser-mais-próprio que se apresenta como uma possibilidade de seu poder-ser em geral, ou seja, o Dasein pode estar em seu poder ser próprio ou impróprio. Essa característica deriva do fato de que o ser aí tem o caráter de estar lançado no mundo. Desse modo, o poder-ser sempre é um poder-ser no mundo que deriva do fato de que o ser aí é ser no mundo.

Mundo não é compreendido por Heidegger como a reunião ou o conjunto do que está à volta e que se destaca de um eu, nem é a somatória dos entes que vivem no mundo, é 
compartilhado. É a determinação ontológica desse mesmo ente na medida em que é nesse que ele se encontra e se percebe como Dasein de tal forma a não poder falar em um antes ou depois, acima ou abaixo. Convicção que coloca de lado toda teoria que prescreva como condição para a tomada de decisões a necessidade do ser humano abster-se desse mesmo mundo.

Se o ser aí é ser no mundo e existe lançado em um mundo de possibilidades, isso implica que, uma vez lançado, o ente pode ou ganhar-se ou perder-se nesse mundo. É importante salientar que isso sempre depende do modo como esse ente se coloca diante das opções que lhe são apresentadas. Isso significa que o Dasein já exerceu mal o seu poder-ser em geral e optou pela impropriedade. Nesse sentido, ele tem a tendência natural de permancer decaído em um poder ser impróprio.

Com o seu mundo, ele [Dasein] está presente para si mesmo, de início e na maior parte das vezes, de tal modo que, a partir do 'mundo' das ocupações, ele já abriu para si mesmo o poder-ser. O poder-ser em que a pre-sença existe sempre já se entregou a determinadas possibilidades. (HEIDEGGER, 1993, p. 56).

Por outro lado, a passagem de um estado no qual ele está decaído para um próprio não ocorre de modo automático ou passivo. É necessária uma interferência, uma atitude do ente que está nessa situação. Ele deve assumir essa outra possibilidade que, contudo, dificilmente é percebida ou notada por ele, pois quase sempre se encontra decaído. Essa situação faz com que essa outra possibilidade permaneça oculta. É digno de nota que uma vez assumida essa possibilidade ela deixa de ser algo que existe no campo das possibilidades e passa a ser efetiva. Contudo, não há garantia que o Dasein permaneça sempre nela e que não voltará ao estado anterior.

A decisão (Entschlossenheit), nesse caso, cumpre um papel fundamental, pois é ela que possibilita ao existente humano, i.e., ao Dasein assumi-la ou não. A decisão, enquanto um modo de ser, não é algo que pode ou não ocorrer dependendo das circunstâncias. Ela exige e se dá pela e através de um novo modo de colocar-se (do Dasein) diante do mundo e de si mesmo, ou seja, ela exige uma mudança na forma como o ente que nós mesmos 
somos compreende-se no mundo. Aliás, ela é que deve possibilitar ao ser aí a tomada de consciência.

Na verdade, essa mesma decisão, ao final, já é uma escolha, mas uma escolha ontológica, não uma escolha qualquer entre as diversas possibilidades que podem apresentar-se no decorrer das circunstâncias cotidianas. Assim, somente nela pode-se escolher existir no poder ser mais próprio ou impróprio. Por outro lado, o encontrar-se decaído, o permanecer fora da propriedade, não exige nenhum esforço ontológico, não necessita de nenhuma decisão.

$\mathrm{Na}$ decisão, enquanto uma escolha, a angústia surge como um aspecto ontológico decisivo, pois ela é que abrirá a possibilidade da autenticidade, ou seja, do poder ser mais próprio. Contudo, uma vez que o ente, via de regra, sempre já se encontra no modo de ser impróprio, para o qual a decisão ontológica não se manifestou, pode-se dizer que a decisão somente se faz presente (no sentido forte do termo) para a propriedade do Dasein.

A angústia tem um papel decisivo nesse processo, pois coloca o existente humano diante da sua possibilidade mais própria. Mas ela é a angústia da escolha ontológica do Dasein lançado no mundo e que na maioria das vezes, como se refere o próprio Heidegger, encontra-se decaído na impessoalidade. Não é, portanto, a angústia por ter deixado passar ou ter perdido essa ou aquela possibilidade concreta. Por outro lado, ela não é um sentimento afetivo no sentido de que se está afetado psicologicamente por algo. Ontologicamente, a angústia é o Dasein afetado pelo mundo em sua totalidade que se lhe abriu.

Nesse estado, o ente que sofre com a angústia não sabe exatamente o que o aflige, onde está o perigo ou o que lhe causa tal sentimento. $\mathrm{O}$ que a provoca é a própria situação hermenêutica (incompreensível naquele momento) do ente lançado e tendo que assumir esse mesmo fato. Assim, o que angustia o Dasein é a própria condição de Dasein que o clamor lhe deu a compreender. Heidegger pergunta: “O que no clamor se dá a compreender de modo essencial, embora nem sempre seja, de fato, compreendido?” (HEIDEGGER, 1993, p. 67) ao que responde algumas páginas à frente: “O que a pre-sença, portanto, dá a compreender seria assim um conhecimento de si mesma". (Ibidem, p. 75)

Com respeito ao angustiar-se, Benedito Nunes dá um excelente relato dessa condição em seu livro Heidegger \& Ser e Tempo: 


\begin{abstract}
Angustiar-se é o não mais sentir-se em casa, a estrutura da subjetividade abalada, sem o encobrimento da mediania do cotidiano e a envolvência da queda [...] Nessas condições, fugimos continuamente da angústia ameaçada pelo poder-ser si mesmo da existência. (NUNES, 2002, p. 20)
\end{abstract}

O não sentir-se em casa é estar fora do conforto da impessoalidade, do público, que se refugia e busca conforto nos afazeres cotidianos. Fora dessa 'casa', desse 'abrigo' a subjetividade está abalada, pois o mundo mostra-se como é, em toda a sua contingência e falta de fundamentos, não há mais nenhum véu que disfarce a derradeira verdade sobre o mundo e sobre a existência humana. Conjuntamente com essa sensação de estar fora de 'casa', sem qualquer coisa que possa dar apoio, conforto ou, até mesmo esperanças, o ser aí foge. Mas essa fuga é dele mesmo e nunca terá sucesso.

A angústia, contudo, não está sozinha nesse movimento, ela trabalha juntamente com o clamor de tal forma a empurrar o Dasein em direção ao seu poder ser mais próprio. “[...] só o clamor sintonizado pela angústia possibilita que a pre-sença se projete para o seu poder-ser mais próprio.” (HEIDEGGER, 1993, p. 63) Empurrar significa, aqui, mostrar-lhe essa possibilidade, pois é necessário que o Dasein decida viver de forma ontologicamente correta. Nada acontece sem que ele faça alguma coisa. O problema é saber, exatamente, qual a forma correta de viver, ou seja, qual o critério que deve ser usado para que se possa ter uma existência autêntica. Heidegger, quanto a isso não dá nenhuma pista. Outros elementos que serão apresentados mais adiante complicam ainda mais a questão, por exemplo, o chamamento da consciência não se dá na forma de um discurso, ou seja, ele não diz o que fazer e como fazer e nem se o que foi feito era correto ou não. Como saber, então se a escolha foi correta? Age-se de modo ético/moral apropriado para cada tipo de situação?

Desse modo, a angústia é fundamental, pois ela é que aponta para o que é importante. Por meio dela é que se revela o que é fundamental. Afinal, ela sintoniza o clamor da consciência e lhe dá um significado, i.e., uma correta orientação. Contudo, não decide pelo Dasein. Por outro lado, não se deve supor que, na angústia, por não ter nenhuma relação com algo conhecido ou esperado, podendo ser interpretado pelo Dasein decaído como um vazio, um nada, não é ele mesmo o que causa a angústia. Se assim fosse 
estaria correto afirmar-se que é a própria falta de uma causa, de um objeto causador a origem desse sentimento. Entretanto, isso não ocorre. O nada, ou vazio, que se revela no angustiar-se ontológico é aquele que revela a totalidade do mundo e a condição do existente humano diante e dentro desse mesmo mundo. Desse modo, não se pode identificar esse mesmo vazio com a falta de algo.

Essa angústia implica em uma necessidade de ação, ou seja, ela revela que se tem de agir e esse agir significa assumir a condição ontológica de que se é Dasein. Contudo, isso não passa despercebido ao ser humano. Heidegger fala de uma espécie de testemunho desempenhado pela consciência com relação ao poder ser mais próprio. Nessa situação ontológica, há um chamamento da consciência a assumir essa possibilidade mais própria. Por outro lado (paradoxalmente) esse chamamento é silencioso, uma convocação silenciosa. Isso complica mais a questão: "O discurso da consciência sempre é apenas e se dá em silêncio." (HEIDEGGER, 1993, p. 59)

Mais adiante, acrescenta que esse silêncio é o clamor e não possui nenhum dado ou conteúdo. O que se dá tem um caráter ontológico e não cognoscitivo, por isso eles (clamor e silêncio) não dizem e revelam nada. "O clamor não relata nenhum dado ou conteúdo. Clama sem nenhuma verbalização. O clamor fala estranhamente em silêncio." (Ibidem, p. 63) A convocação é silenciosa, porque ontológica, caso contrário, seria psicológica. Revela nada no sentido epistemológico, ou seja, não dá a conhecer à consciência ou revela algum conteúdo, mas preparam para tal.

Esse chamamento, testemunho, essa voz que fala sem palavras é mais uma situação hermenêutica, um momento no qual se compreende, por um lado, a própria finitude do existir e, por outro, que se existe nessa mesma finitude e se é delimitado por ela. O clamor é o testemunho ontológico da consciência desse débito essencial que, também, não é assumir um sofrimento ou algo do gênero.

O clamor da consciência possui o caráter de aclamação da pre-sença para o seu poder-ser-si-mesmo mais próprio e isso no modo de conclamar o seu ser e estar em débito mais próprio. (HEIDEGGER, 1993, p. 54) 
Todavia, Heidegger ressalta que o assumir não é um movimento introspectivo no qual o sujeito do conhecimento se dá conta de si e de sua existência de tal forma a submetêla a uma avaliação e culpar-se por algo. "Assumir este não significa carregar-se de culpa por falta ou omissão.” (HEIDEGGER, 1993, p.75) Isso quer dizer que há uma responsabilidade prévia, ontológica, nesse vir a si e tal prioridade diz respeito à autenticidade. Lê-se em Ser e Tempo um pouco mais adiante: “A pre-sença só pode perderse, ganhar-se ou ainda não se ter ganho porque, segundo seu modo de ser, ela é uma possibilidade própria, ou seja, é chamada a apropriar-se de si mesma."(HEIDEGGER, 1997, p. 78)

O sentir-se em débito ou culpado é o testemunho de que estamos fora do campo do poder ser mais próprio. Esse sentir-se em débito, como todos os outros elementos, é uma culpa e débito ontológicos. Não derivam de uma situação ou circunstância qualquer, mas surgem da situação hermenêutica na qual o Dasein compreende-se como ser no mundo lançado na existência. Portanto, não nascem de uma espécie de arrependimento por erros ou omissões que podem compor o comportamento. Culpa, dívida e débito são momentos ontológicos fundamentais que revelam a necessidade de completude do existente humano que implica, necessariamente, em um colocar-se de modo diferente com relação a si mesmo, aos outros seres humanos e ao próprio mundo. Salienta-se que esse colocar-se de modo diferente é uma postura de caráter ético/moral.

Assim, pode-se pensar que débito, dívida e culpa funcionam como critérios para poder identificar-se o existente humano em um modo de vida autêntico ou não e, assim, agindo de forma moralmente correta ou não consigo e com seu semelhante. Contudo, esses elementos não revelam nenhum conteúdo à consciência. A totalidade do mundo e a condição ontológica do ser humano revelam-se com toda a sua força. Para pensá-los como critérios é necessário poder pensar essa mesma totalidade do mundo que revela, mas não dá nada a conhecer. Essa é uma dificuldade que, aqui, não será analisada.

Agora, como pode identificar-se uma espécie de moral ou ética nesse processo ontológico? A consciência que fala silenciosamente revelando uma dívida e débito ontológico pressupõe uma espécie de comprometimento ético ou moral? Desse modo, é uma falta que o acompanha desde sempre e estará sempre presente, com ou sem a consciência (psicológica), pois, mesmo que o homem coloque-se em uma posição na qual 
esteja em seu ser mais próprio, esse estar não garante nada; não garante que o homem nunca mais se perca no impessoal e exista em um modo de ser impróprio. O problema é que essa consciência que chama e invoca silenciosamente não dá orientações ou ordens, ou seja, não diz o que fazer, como fazer ou, ainda, se o que foi feito está correto, não avalia nada. Todavia, ela apenas dá as condições necessárias para tal. Então, a consciência revela, aponta o caminho, mas não dá orientações. A situação hermenêutica na qual ela fala abre o mundo e a existência como ek-sistir. É essa abertura uma espécie de ética ou moral? Não, mas revela o ético e o moral como determinantes do modo como se está nessa mesma abertura.

É interessante compreender a relação entre o cuidado e os modos de ser do existente humano. O cuidado é apresentado por Heidegger como o ser do Dasein na medida em que nele se fundam e dele derivam todos os outros momentos essenciais e, por isso, ontológicos do ente que se é. Por outro lado, o cuidado não especifica um modo de ser determinado, mas é o fundamento de todos os possíveis modos de ser. Assim, ele não é um tipo de estrutura ética ou moral, mas determina a perspectiva dos comportamentos éticos e morais. Então, ao Dasein um ser e estar em débito ontológico inerente à estrutura do cuidado e que determina o seu modo de ser na abertura. Nesse sentido, afirma-se que o cuidado é a origem, em si mesmo, da expressão ético-originária do existente humano. Diz Heidegger:

Um ente cujo ser é cura não apenas, de fato, carrega um débito, como no fundo de seu ser, é e está em débito. Apenas este ser e estar em débito oferece a condição ontológica para que a pre-sença, existindo de fato, possa ser e estar em débito. Esse ser e estar em débito essencial é, de modo igualmente originário, a condição existencial da possibilidade do bem e do mal "morais", ou seja, da moralidade em geral e de suas possíveis configurações factuais. Não se pode determinar o ser e estar em débito originário pela moralidade porque ela já o pressupõe. (HEIDEGGER, 1993, p. 74)

Está claro, por outro lado, que qualquer possibilidade de um comportamento moral relaciona-se com ser e estar em débito. Logo, atender a essa mesma condição implicará em um comportamento moral específico. Algo que pode reforçar e ajudar a compreender o cuidado como a expressão ético-originária do existente humano é lembrarmos dos momentos existenciais que o constituem. Heidegger chegará à apresentação da estrutura do 
cuidado depois de explicitar, mediante uma analítica existencial, os três momentos ontológicos fundamentais que constituem o ser humano: a existencialidade, a facticidade e a decadência (HEIDEGGER, 1997, p. 255).

Levando em consideração o fato de que o cuidado determina o que e como se é no mundo e que esse mesmo mundo é compartilhado, pois o ser aí é sempre ser com, i.e., um ente que vive e convive com outros seres aí, a existencialidade, a facticidade e a decadência, por serem modos de ser são, também, modos éticos/morais do existente humano ser no mundo. Por outro lado, ontologicamente, não há como falar em um Dasein que vive isolado de outros entes (sejam eles do tipo que forem). Abster-se do mundo, do convívio humano, isolar-se é impossível. "Na base do ser-no-mundo determinado pelo com, o mundo é sempre o mundo compartilhado com os outros. O mundo da pre-sença é mundo compartilhado. [...] O ser-em é ser-com os outros". (HEIDEGGER, 1997, p. 170). Mesmo o isolamento físico já é uma forma de opção de convívio e compartilhamento ontológicos de mundo. E, somente é possível, exatamente pelo fato do homem ser originariamente ser em e ser com. Essa ideia deve ser mantida no horizonte das discussões desse trabalho para que fique mais compreensível a ligação entre ética/moral e os modos de ser existenciais do Dasein.

Da existencialidade, enquanto estrutura constituinte do cuidado deriva a caracterização do Dasein como um poder ser, o qual somente pode ser exercido no mundo. Acrescenta-se a isso que o existente humano, interpretado ontologicamente, não existe somente no mundo com outros entes, mas é determinado por esse mesmo poder ser, pois, a ele pertence uma compreensão de ser de algum modo ou de outro. Desse modo, o existente humano não existe indiferente no mundo. Existir, do ponto de vista ontológico, é algo que lhe diz respeito, pois está a seu cargo decidir-se por determinadas possibilidades.

Um esclarecimento faz-se necessário nesse momento: o cuidado, apesar do nome sugerir, não identifica um modo de comportamento ético/moral no sentido tradicional. Esse termo deve ser interpretado ontologicamente. Como diz Heidegger, difere de toda a interpretação ôntico-teórica, pois não é uma generalização que afirma "[...] que todos os comportamentos e atitudes do homem são 'dotados de cura' e guiados por uma “dedicação"” (HEIDEGGER, 1997, p. 265). O cuidado é uma generalização de caráter ontológico e a priori. "A generalização é de ordem ontológica e a priori”. (HEIDEGGER, 
1997, p. 265), ou seja, ela é subjacente ao Dasein e determinante daqueles horizontes nos quais o existente humano encontra-se como homem que tem que assumir e tomar certas atitudes, ou seja, não há como fugir ou ignorarmos essa constituição e sua influência. Para reforçar, cita-se: "Ela não significa propriedades ônticas que continuamente aparecem, e sim a constituição ontológica sempre subjacente”. (HEIDEGGER, 1997, p. 265)

Heidegger até mesmo julga ter encontrado um testemunho, em suas palavras, préontológico, da existência do cuidado, ou melhor, dessa compreensão. Todavia, por ser préontológico, ele é apenas um registro que ainda deve ser submetido a uma interpretação ontológica. Por outro lado, o seu valor reside exatamente nisso, em ser esse testemunho e que se submetido a uma interpretação ontológica revelará o verdadeiro ser do Dasein como cuidado.

Então, seja lá o que for o ser aí ele é uma criação do cuidado. ${ }^{3}$ A estrutura do cuidado reforça a ideia de que ele é a expressão ético-originária do homem. Enquanto serno-mundo o Dasein está igualmente sempre condicionado historicamente. Ele já se encontra em meio a possibilidades de existir de um modo ou de outro. Isso indica o caráter de ser em que lhe pertence, ou seja, a facticidade inerente ao ser humano. Ser no mundo também é sempre ser com outros entes, quer tenham ou não o caráter de Dasein, i.e., o existente humano é sempre ser junto a outros entes. Isso indica o caráter da decadência que pertence ao cuidado.

O Dasein, enquanto existente, projeta-se continuamente e constantemente em possibilidades e sempre existe em razão de um poder ser para o qual ele se projeta (que pode ser autêntico ou inautêntico), ou seja, existe para um possível modo de existir que é um comportamento ético/moral. Dito de outro modo, o ser aí não existe fora da moralidade, se assim pode-se falar. Mas esse existir pode ser tanto autêntico quanto inautêntico.

Heidegger caracteriza o poder ser autêntico como um preceder a si mesmo. "Do ponto de vista ontológico, ser para o poder-ser mais autêntico significa: em seu ser, a presença já sempre precedeu a si mesmo.” (HEIDEGGER, 1997, p. 255) Significa, ontologicamente, que o ser aí está sempre além de si mesmo. Existe projetado, mas projetado para o seu poder ser. A existencialidade é um preceder a si mesmo, um projetarse para, um estar além de si mesmo que o constitui. 
Entretanto, o Dasein sempre existe em um mundo. O projetar-se para o poder ser é sempre um projetar-se igualmente em um mundo. Dessa forma, o preceder a si mesmo não deve significar a tendência isolada de um ente sem mundo. Pelo contrário, o preceder somente é possível pelo fato do ser aí ser no mundo. "Apreendido em sua plenitude, o preceder a si mesmo da pre-sença diz: preceder a si mesma por já ser-no-mundo". (HEIDEGGER, 1997, p. 256) O preceder-se ocorre de forma contínua. Com isso, Heidegger mostra outro momento ontológico fundamental que constitui a estrutura ontológica do ser humano, qual seja a facticidade. Momento estrutural que explicita o fato de que o existente humano pertence a um mundo e a sua ligação com a existencialidade que, igualmente, lhe pertence.

Com a intenção de caracterizar o terceiro momento e mostrar o seu nexo com a existencialidade e com a facticidade, Heidegger afirma: "E, por conseguinte, o existir de fato da pre-sença não está apenas lançado indiferentemente num poder-ser-no-mundo, mas está sempre empenhado no mundo das ocupações”. (HEIDEGGER, 1997, p. 257). O que indica que existindo em um mundo, o homem, sempre é ser junto a outros entes (dotados ou não de caráter de Dasein), i.e., o existente humano existe sempre decaído, em estado de decadência. Por conseguinte, uma vez que as estruturas que formam o Dasein são ontológicas por determinar o modo do existente humano ser em um mundo, o autor procura mostrar que tais estruturas não ocorrem ao acaso.

O cuidado é apresentado como o ser do Dasein porque ele é o termo que apreende formalmente a totalidade existencial das estruturas ontológicas do existente humano, i.e., é a unidade dessas estruturas. Diz igualmente que o existente humano precede-se a si mesmo (existencialidade), por já ser-em um mundo (facticidade) junto a outros entes (decadência). Assim, Heidegger pode dizer que o ser aí, enquanto ser no mundo, é essencialmente cuidado e é determinado pela existencialidade, facticidade e decadência.

Assim, é importante salientar que com o uso do termo "cuidado" o autor procura afastar significações de caráter ôntico que possam ser atribuídas a essa palavra no sentido, por exemplo, de cuidar de algo ou de alguém. O cuidado tem um significado puramente ontológico existencial. (HEIDEGGER, 1997, p. 257). O cuidado não significa a ocupação ou preocupação de alguém consigo mesmo ou para com outros, mas o ocupar-se e pré 
ocupar-se ontológico do existente humano lançado em um mundo junto a outros entes. $\mathrm{O}$ cuidado, também, não diz respeito a atitude isolada de um sujeito.

Então, se é no preceder a si mesmo que pertence à estrutura do cuidado, que está indicando que o Dasein se projeta sempre em razão de seu poder-ser, se a totalidade da estrutura do cuidado se acha "[...] do ponto de vista existencial a priori, 'antes' de toda 'atitude' e 'situação'[...]”. (HEIDEGGER, 1997, p. 258); será no preceder a si mesmo que está indicada a condição ontológico existencial de possibilidade de ser livre para as possibilidades existenciárias, as possibilidades de fato para as quais o existente humano se decide.

Assim, mostra-se que é inerente àquela estrutura existencial do Dasein a possibilidade de uma ética/moral e que mesmo Heidegger não tendo como objetivos explicitar, em Ser e Tempo, que foi a obra base dessa exposição, uma teoria ético/moral parece óbvio que todo o seu discurso desenvolvido naquela obra pressupõe e revela um comprometimento ético/moral. E isso diz respeito, primeiramente, a tarefa que o existente humano deve ter para consigo, qual seja, assumir a sua condição de Dasein. O que implicará em um colocar-se de modo diferenciado no mundo, ou seja, comportar-se de modo totalmente diverso.

Partindo da ideia de que na impessoalidade o existente humano não escolhe de modo legítimo pelas possibilidades que the são apresentadas no mundo e que isso caracteriza o modo de ser inautêntico ou impróprio, sair dessa condição deve possibilitar um comportamento adequado do ponto de vista ético/moral. Pois, sair dessa condição implica em colocar-se em um modo de ser no qual o ser humano compreende-se como correto (ontologicamente correto). E, assim, reorganizando e reestruturando o seu espaço comum. Numa situação dessas, obviamente, o tratamento de questões práticas como citadas anteriormente, como aborto, pena de morte e meio ambiente serão avaliadas por perspectivas totalmente diferentes. Pois, agora, essas questões não dizem respeito a um sujeito do conhecimento que de modo isolado capta de algum modo o mundo a sua volta. Essas questões dizem respeito ao modo como o ente humano compreende-se dentro do mundo e a si mesmo. A situação fenomenológica-hermêutica que se abrirá possibilitará o comportamento ético/moral totalmente diferente. 
Com isso, julga-se poder ter mostrado a pertinência de um pressuposto ético/moral ao discurso heideggeriano tal qual é feito em Ser e Tempo e a sua importância e ligação para o desenvolvimento de uma filosofia moral. O caminho que deve ser percorrido aponta para a construção de uma antropologia filosófica ${ }^{4}$ na qual a técnica, enquanto um modo de encontro dos entes, possa ser repensada em suas origens. Pois, enquanto a 'perfeita objetivação da representação' ela encobre a experiência filosófica de mundo fazendo com que o ser humano não se compreenda a si mesmo e nem a sua relação com o meio ambiente de modo adequado. 


\section{Notas:}

${ }^{1}$ Professor Adjunto do Curso de Filosofia da Universidade Federal da Fronteira Sul (UFFS), Chapecó, Santa Catarina, Brasil.

${ }^{2}$ Contudo, isso mesmo que empurra para a decisão que resultará em um assumir a própria existência não decorre de um conhecimento de si mesmo e do mundo e dos outros entes, mas é uma condição (autêntica) para tal.

${ }^{3}$ Pois dele deriva a estrutura do Dasein, nas quais se encontra a orientação dos modos de ser do existente humano e, portanto, de seu comportamento com relação ao seu meio.

${ }^{4}$ Ernilso Stein é um dos pioneiros nessa tentativa. Ver sua obra Antropologia Filosófica: questões epistemológicas. 


\section{Referências bibliográficas:}

HEIDEGGER, Martin. Carta sobre o humanismo. Lisboa: Guimarães Editores, 1987.

Ser e Tempo I. Petrópolis: Editora Vozes, 1997.

Ser e Tempo II. Petrópolis: Editora Vozes, 1993.

NUNES, Benedito. Heidegger \& Ser e Tempo. Rio de Janeiro: Jorge Zahar, 2002.

STEIN, Ernildo. Antropologia Filosófica: questões epistemológicas. Ijuí: Ed. Unijuí, 2009.

THIELE, Leslie Paul. Martin Heidegger e a política pós-moderna: meditações sobre tempo. Lisboa : Instituto Piaget, 1995. 